\title{
ACOMPANHAMENTO TERAPÊUTICO, CLÍNICA E ATENÇÃO PSICOSSOCIAL: UMA RELAÇÃO POSSÍVEL? REFLEX ̃̃O CRÍTICA SEGUNDO A HERMENÊUTICA DIALÉTICA DE JÜGEN HABERMAS
}

\author{
THERAPEUTIC ACCOMPANIMENT, OUTPATIENT CLINIC AND \\ PSYCHOSOCIAL CARE: A POSSIBLE RELATIONSHIP? CRITICAL REFLECTION \\ ACCORDING TO JÜRGEN HABERMAS HERMENEUTIC DIALECTIC
}

Regina Célia Fiorati

Universidade de São Paulo, Ribeirão Preto/SP, Brasil

\begin{abstract}
RESUMO
A reflexão sobre como se organiza a oferta terapêutica nos serviços extra-hospitalares da rede pública de saúde mental tem mostrado que a organização do trabalho coloca o saber médico-psicológico como componente privilegiado dos programas terapêuticos, impõe uma cisão teórico-prática entre o tratamento clínicomedicamentoso-psicológico e as estratégias de reabilitação psicossocial, e elegem os primeiros como dispositivo central de seus programas, em detrimento das ações psicossociais. À luz da Teoria da Ação Comunicativa de Jürgen Habermas situa-se o problema como consequência de extrema tecnificação das práticas terapêuticas, selecionadas, ideologicamente, segundo uma racionalidade instrumental, na qual as práticas respondem a imperativos técnicos, ignorando o elemento humano e social, provocando uma dicotomização entre a clínica e a atenção psicossocial, como se fossem práticas dissociadas nos projetos terapêuticos. Aponta-se para a prática do Acompanhamento Terapêutico como possibilidade concreta de reunião dessas esferas da ação dissociadas e de superação da dicotomização entre clínica e atenção psicossocial.
\end{abstract}

Palavras-chave: acompanhamento terapêutico; serviços de saúde mental; saúde mental; reabilitação; clínica.

\begin{abstract}
Reflections about the therapeutic offer is organized in extra-hospital services within the public mental healthcare network have shown the way work is organized puts forward medical-psychological knowledge as a privileged comonent of therapeutic programs, imposes a theoretical-practical split between clinical-medicationpsychological treatments and psychosocial rehabilitation strategies, and select the former as the central device of its programs, to the detriment of psychosocial actions. In the light of Jürgen Habermas' communication theory, the problem is established as a consequence of the extreme technification of therapeutic practices, ideologically selected in line with an instrumental rationality, in which the practices respond to technical imeratives, ignoring the human and social element, provoking a dichotomization between the clinic and psychosocial care, as if they were dissociated practices in therapeutic projects. Therapeutic Accompaniment is indicated as a concrete possibility of having these dissociated action spheres meet and of overcoming the dichotomization between outpatient clinic and psychosocial care.
\end{abstract}

Keywords: therapeutic accompaniment; mental healthcare services; mental health; rehabilitation; clinic.

\section{Introdução}

Os serviços extra-hospitalares têm seu advento a partir dos Movimentos de Reforma Psiquiátrica, no mundo e no Brasil. Na Europa Ocidental e Estados Unidos, em meados do século XX, por meio de vários movimentos de questionamentos sociais, reordenações ético-políticas e reformas institucionais foram preconizadas. Com base no movimento que questiona o modelo psiquiátrico tradicional foram criados equipamentos, ferramentas e iniciativas que procuraram substituir as formas de tratamento psiquiátrico que se apoiavam na estrutura anacrônica e iatrogênica do manicômio e das práticas de exclusão total do portador de sofrimento psíquico, apartando-o de seu ambiente sociofamiliar, confinando-o em espaços restritivos com características de asilo definitivo.

No Brasil, o Movimento de Reforma Psiquiátrica foi iniciado no final da década de 70 , e seu maior 
desenvolvimento deu-se nas décadas de 80 e 90, culminando com a criação dos primeiros Núcleos de Atenção Psicossocial (NAPS), com Centros de Atenção Psicossocial (CAPS), com Centros de Convivência, com hospitais-dia, entre outros, tais como serviços extra-hospitalares de saúde mental (Amarante, 1995).

A proposta da Reforma Psiquiátrica, em seus princípios norteadores, refere-se à ampliação do campo da clínica, investindo em práticas não mais hospitalocêntricas e medicocentradas e, por meio de diretriz central, qualifica a atenção como psicossocial, redefinindo o sentido de saúde como produto não mais de um indivíduo, mas do coletivo. Há mudança de proposta no campo de atuação profissional como aquela que se coloca na interface entre o subjetivo e o social, entre o que diz respeito às singularidades e às formas de apropriação dos espaços urbanos e públicos e às multiplicidades culturais. Nessa direção, os serviços extra-hospitalares de saúde mental, ao apontarem para a função prioritária de substituição do modelo anacrônico do asilo, da terapêutica hospitalar e da prática de exclusão social, colocamse, diretamente, diante do investimento em um funcionamento articulado dos diversos equipamentos de saúde, com a passagem para uma organização interdisciplinar, dando relevância à intervenção no território, entendendo por território uma noção que vai além da definição de um espaço físico e geográfico, mas como estrutura dinâmica sociopolítica de difusão de saberes, valores e culturas. É espaço multidimensional de interação humana intersubjetiva e social (Almeida \& Oliver, 2001).

No entanto, encontramo-nos, muitas vezes, com serviços extra-hospitalares de saúde mental cujos projetos terapêuticos não enfocam prioritariamente a inserção do usuário na comunidade, ponto que permanece central no projeto da Reforma Psiquiátrica. Os programas e os projetos terapêuticos, nesses serviços, privilegiam o sistema de tratamento apoiado nas concepções da clínica médico-medicamentosa e psicológica, fixada principalmente nos consultórios, e desvalorizam as práticas terapêuticas que sediam sua ação no território, na comunidade, utilizando os recursos do cotidiano e do social e, dentre essas, ações que constituem estratégias de reabilitação psicossocial (Fiorati, 2006).

As equipes, quando consultadas sobre essa questão, referem que há carência de recursos humanos e materiais nos serviços e que devem priorizar o tratamento do paciente, como se ações psicossociais não constituíssem tratamento. Referem-se, ainda, à carência de locais que trabalhem a inclusão social do usuário. A referência é colocada em algum lugar inexistente e imaginário que, certamente, não pertence ao espaço do serviço extra-hospitalar de saúde mental.

Os serviços extra-hospitalares de saúde mental, entretanto, restringindo as práticas psicossociais, que se desenvolvem na comunidade, no território e na cultura, deixam um vazio assistencial para seus usuários, que se veem, frequentemente, desprovidos de recursos para produzirem suas vidas na cultura ao ficarem dependentes, psicossocialmente, do serviço extrahospitalar e fazendo desse sua rede de relacionamentos interpessoais. Isso fica claro na dificuldade que a equipe de profissionais dos serviços encontra para dar alta aos pacientes, sendo que alguns usuários permanecem em Centros de Atenção Psicossocial por anos, ou mesmo décadas, nos serviços de caráter ambulatorial (Wetzel, 2005).

Se essa realidade se mostra tão evidente nos serviços extra-hospitalares e constitui fator que dificulta a alta do usuário e sua inserção na vida comunitária, era de se supor que os programas terapêuticos deveriam levá-la em consideração na elaboração dos projetos terapêuticos que disponibilizam. Por que, então, as ações psicossociais são proteladas e remetidas à outra dimensão de atenção em saúde mental ou social?

As práticas que repetem a lógica fundada a partir dos saberes da medicina são mais valorizadas, técnica e socialmente, tanto pelos profissionais quanto pelos usuários que passam a reproduzir as crenças e idealizações dos profissionais e do sistema de conhecimento que determina a racionalidade pela qual essas práticas são legitimadas como detentoras de mais verdade que outras.

Dois enfoques presentes na obra do filósofo Jürgen Habermas são enfatizados nesse trabalho por contribuírem para o entendimento dos fatores que permeiam a construção dos projetos terapêuticos nos serviços extra-hospitalares de saúde mental nos quais os tratamentos apoiados na tecnologia médico-psicológica são priorizados em relação às práticas psicossociais. O primeiro enfoque diz respeito à denúncia da cultura na sociedade capitalista ocidental contemporânea, que se desenvolveu a partir do capitalismo tardio. Denominando essa forma de organização social tecnocrática, o autor afirma que, nesse contexto, a ciência e a técnica passam a constituir dispositivos de legitimação em si mesmos, transformando-se em dispositivos ideológicos nos quais todas as ações das esferas do social vão se apoiar. A ciência e a técnica, portanto, ao se constituírem enquanto ideologia em si mesmas, ignoram sua relação com os interesses sociais e a esfera política das ações, propõem uma racionalidade que responde apenas a imperativos técnicos e que se sobrepõe à racionalidade fundada na esfera da 
interação humana. A essa racionalidade que procede de forma calculada de modo a obter a otimização de meios para se alcançar fins determinados, Habermas (1987) denomina instrumental.

Habermas (1988), entretanto - e este constitui o segundo enfoque a ser salientado, resgata o valor da racionalidade apoiada em ação comunicativa, em contraposição à racionalidade instrumental, por meio da qual uma forma comunicacional é pensada no sentido de orientar as ações, que preconiza a construção de projetos dialógica e interdisciplinarmente construídos, permeando os esquemas de validação discursiva, linguística e intersubjetivamente mediados e que expressam as experiências concretamente vividas, valores, interesses e necessidades das pessoas em sociedade. Ou seja, para Habermas, é possível uma construção coletiva apoiada sobre um diálogo, no qual os discursos possam relacionar-se entre si com o mesmo estatuto e só assim haveria comunicação livre de coerções.

$\mathrm{O}$ primeiro enfoque enfatizado ajuda a compreender porque os tratamentos clínicos médicopsicológicos, ao se apoiarem em conhecimento científico positivo e na racionalidade instrumental, são mais valorizados que as ações da atenção psicossocial que, por sua vez, vão apoiar sua tecnologia na dimensão das esferas da interação humana. No que diz respeito ao segundo enfoque abordado, ao se entender que os projetos terapêuticos desses serviços constituem um tipo de consenso normativo, tenta-se compreender os meios pelos quais as equipes validam discursivamente as opções terapêuticas que efetuam e se o fazem por meio de disposição dialógica e interdisciplinar.

À luz do referencial teórico-filosófico habermasiano, propõe-se a reflexão sobre o processo pelo qual os projetos terapêuticos nos serviços extra-hospitalares de saúde mental, ao privilegiarem determinadas práticas terapêuticas e secundarizarem outras, por meio de um processo de extrema tecnificação das práticas e procedimentos terapêuticos disponibilizados aos usuários, causam uma hierarquização valorativa entre as práticas terapêuticas, a partir da qual os profissionais dos serviços investem mais valor social às práticas clínicas estrito senso, idealizadas como detentoras de mais cientificidade, em detrimento de práticas psicossociais que, ao se aproximarem da dimensão do cotidiano, são desinvestidas de valor social e técnico. Dessa forma, ocorre uma dicotomização entre as práticas clínicas e as ações de reabilitação psicossocial que passam a ser consideradas como dissociadas nos projetos terapêuticos, como se fossem constituintes de esferas diferentes e divorciadas nas ações terapêuticas.
O acompanhamento terapêutico é um procedimento clínico que apresenta a característica predominante de se realizar utilizando os dispositivos do cotidiano, do território e da cultura como elementos centrais de recursos terapêuticos. Ou seja, essa prática terapêutica, ao se realizar, prioritariamente, nos espaços públicos e coletivos de produção da vida social, mostra-se como recurso privilegiado de atenção psicossocial ao mesmo tempo em que trata clinicamente o sujeito em sofrimento. Dessa forma, apresenta-se, nesse trabalho, o acompanhamento terapêutico, como a possibilidade, por excelência, de reunir as esferas de ação que se apresentam muitas vezes dissociadas nos projetos terapêuticos dos serviços extra-hospitalares de saúde mental, e como forma de superação da dicotomização entre as ações clínicas e as ações constituintes da atenção psicossocial.

\section{Clínica e reabilitação psicossocial: uma dicotomia?}

Segundo Onocko-Campos e Furtado (2006), os Centros de Atenção Psicossocial (CAPS), como representantes desses serviços extra-hospitalares de saúde mental, configuram-se como serviços comunitários, ambulatoriais e regionalizados nos quais os pacientes deverão receber consultas médicas, atendimentos terapêuticos individuais e/ou grupais podendo participar de ateliês abertos, de atividades lúdicas e recreativas promovidas pelos profissionais do serviço, de maneira mais ou menos intensiva e articulada em torno de um projeto terapêutico individualizado, voltado para o tratamento $\mathrm{e}$ reabilitação psicossocial, devendo também haver iniciativas extensivas aos familiares e às questões de ordem social presentes no cotidiano dos usuários. (Onocko-Campos \& Furtado, 2006, p. 1055)

Dessa forma, pressupõe-se que, para que os serviços extra-hospitalares venham realmente a ser serviços substitutivos à estrutura teórico-prática do modelo clínico hegemônico, hospitalar e biomédico, são necessárias algumas rupturas de ordem ética, política e epistemológica com o saber que legitima a prática tradicional apoiada no dispositivo técnicocientífico médico-psicológico (Amarante, 1996).

Preconiza-se, portanto, a partir dos projetos da Reforma Psiquiátrica, a importância e a priorização de modos de cuidado que se pautem no modelo de atenção psicossocial, cuja ação primordial é a intervenção no território e a inserção do portador de sofrimentos psíquicos na vida coletiva e comunitária (Amarante, 2007). 
Entretanto, conforme ressaltado acima, parcela importante dos serviços públicos extra-hospitalares de saúde mental não enfoca, prioritariamente, a inserção na comunidade. Nesses serviços, os tratamentos clínicos médico-psicológicos, que se caracterizam por reproduzir tecnologia gerada no interior do paradigma da ciência moderna, centrados nos consultórios, nos espaços internos exclusivos dos próprios serviços, são privilegiados, ao mesmo tempo em que há secundarização das práticas terapêuticas que se realizam, principalmente, no território, na interface com as redes sociais que caracterizam as estratégias da reabilitação psicossocial (Fiorati, 2006).

Peduzzi (1998) realça a hierarquia valorativa construída a partir da prática médica e daquelas que a reproduzem, ao mesmo tempo em que desvaloriza as práticas de cuidado que se distanciam dessa tecnologia. Para a autora, as práticas médicas são "paramentadas" de um valor absoluto como detentora da verdade científica e, portanto, como representativa da verdadeira técnica eficiente. Da mesma forma, práticas terapêuticas, que se aproximam da dimensão do cotidiano e se realizam fora dos espaços ritualísticos da tecnologia médica, são relegadas à dimensão periférica e profana do senso comum.

De acordo com Habermas (1987), a ciência e a tecnologia, ao passarem a funcionar como as principais forças produtivas e de coesão ideológica, produzem uma colonização da dimensão da interação humana pela tecnificação, e a sociedade torna-se a esfera da administração total. Da mesma forma, o progresso autônomo da ciência e da técnica passa a determinar o desenvolvimento da vida social, os aparelhos de poder instrumentalizam-se como órgãos executivos da razão científica e técnica, e o Estado, ao absorver essa racionalidade, passa a orientar suas decisões não pela prática, mas sim tecnicamente. Os efeitos dessa organização social, segundo o filósofo, são: a despolitização das massas, o ocultamento dos verdadeiros interesses que subjazem a esse funcionamento social e o impedimento da opinião pública de manifestar-se em questionamentos críticos, pois, na medida em que os fundamentos do funcionamento tecnocrata respondem somente a imperativos de uma racionalidade técnica, esses fundamentos tornam-se imunes a qualquer contestação. Habermas (1987) alerta, ainda, que se a ciência e a técnica se autolegitimam, o risco maior é a invalidação na consciência dos homens da distinção entre ação instrumental e ação comunicativa. O homem passa a se auto-objetivar na perspectiva exclusiva da ação instrumental e do comportamento adaptativo e a ação comunicativa é absorvida pela ação instrumental.
Habermas (1988), contudo, traz a proposição de racionalidade apoiada em ação comunicativa que se contrapõe à racionalidade instrumental. A racionalidade comunicativa, portanto, permeia a dimensão na qual ocorrem os processos da interação humana, que se realizam pela intercomunicabilidade apoiada nas trocas intersubjetivas e simbolicamente mediadas pela linguagem. De acordo com o autor, é essa racionalidade que possibilita a construção de projetos sociais dialogicamente instaurados, isto é, construção coletiva apoiada no diálogo, a partir do qual os discursos têm o mesmo estatuto de validação. Dessa forma, o filósofo propõe uma ação comunicativa livre e isenta de coações, que se colocaria na base da formação de consensos normativos para viabilização de projetos sociais multiculturais e processo civilizatório apoiado em valores de solidariedade social.

Ora, um projeto terapêutico se caracteriza por processo de formação de consenso normativo, constitui uma construção coletiva envolvendo técnicos de saúde, usuários e familiares que pretendem estabelecer algumas normas de atuação frente a outros homens e a outras mulheres acometidos por sofrimento psíquico. Entretanto, pergunta-se qual o estatuto que cada discurso adquire no encontro consensual que busca construir e desenvolver o plano terapêutico. De acordo com a argumentação enfocada, as disposições discursivas que se apoiam nos dispositivos técnicocientíficos, que apenas reproduzem a tecnologia médico-psicológica, tendem a se sobrepor e a adquirir a legitimidade da objetivação necessária, remetendo os discursos que focalizam as ações psicossociais, ao não alcançarem o mesmo estatuto de legitimidade, ao campo das ações possíveis, mas não necessárias. Dessa forma, os projetos terapêuticos construídos nos serviços extra-hospitalares de saúde mental arriscam não contemplar a dialogicidade necessária para compor projetos apoiados na interdisciplinaridade dos saberes e práticas como preconizam as diretrizes da Reforma Psiquiátrica.

As consequências para as ações terapêuticas são imediatas, ou seja, os arsenais técnico-científicos aplicados de forma autolegitimável pelas equipes tomam como objeto de sua intervenção um sujeito idealizado e objetivado, o doente, sujeito descrito pela literatura científica como igual e imutável em qualquer lugar e tempo, ao qual são aplicadas técnicas que se autorreproduzem como provadamente eficientes pelos mesmos dispositivos que as legitimam.

A prática clínica das ciências médicas, segundo Ayres (2007), apoia-se na racionalidade instrumental, isto é, um dispositivo prático-discursivo voltado para o domínio e utilização de meios determinados para fins 
particulares, visando ao êxito técnico que representa domínio instrumental sobre a doença, perdendo de vista as bases normativas que a fundamentam, ao mesmo tempo em que absolutiza as relações entre meios e fins sobre as quais se construiu. Dentro dessa lógica, a prática médica objetifica o doente, na medida em que clínica resume-se na "aplicação de um arsenal científico-tecnológico sobre um substrato passivo, o usuário ou a população" (p.53) e nesse esquema só há lugar para um sujeito: o próprio técnico.

O mesmo autor afirma que as práticas de saúde partem de uma concepção de sujeito como portador de essencialidade com pretensões universalizáveis, absoluta em qualquer lugar e em qualquer tempo. Essa é a visão predominante das concepções científicas positivas, nomológicas que emergiram da tradição iluminista e se consolidaram na modernidade. Concepções que pautam a legitimação imediata dos arsenais técnicos, igualmente absolutizados, aplicáveis sobre um indivíduo idealizado e objetificado, na concepção dominante, representada pela biomedicina. As práticas clínicas, ao se pautarem na concepção de sujeito imutável, atemporal e permanente, preconizam técnica que se auto-reproduz sem contemplar as reais necessidades daquele a qual se destina: o usuário. $\mathrm{O}$ sujeito, diz o autor, só se constrói na relação com o outro, é no encontro intersubjetivo, contingencialmente constituído, que se fundam as subjetividades. Se não existe um sujeito imutável e permanente, suas experiências existenciais, mesmo o adoecimento, assim como as formas de tratamento, transformamse histórica e contextualmente. Dessa forma, não pode haver uma técnica única e atemporal, aplicável permanentemente, sem levar em consideração as novas formas de subjetivação que se traduzem nos vários contextos. Sendo assim, as verdades são sempre provisórias, porque são, sobretudo, fruto de consensos (Ayres, 2001).

Ayres (2001, p.50), no entanto, não propõe o abandono da ação instrumental, mas a submissão dessa a uma racionalidade prática, na qual a clínica se produza no encontro autêntico entre dois sujeitos que visam ao sucesso prático, que se traduz na construção de um projeto de felicidade: "A experiência da saúde envolve a construção compartilhada de nossas ideias de bem-viver e de um modo conveniente de buscar realizá-las na nossa vida em comum".

Habermas (1988), nesse sentido, apresenta crença na possibilidade emancipatória da civilização e na abolição da dominação de homens sobre homens sem, no entanto, prescindir da dominação sobre a natureza, pois o filósofo considerava a ação instrumental direcionada a fins determinados como um a priori da espécie humana. Assim como considerava a interação linguisticamente mediada, outro a priori, sendo esse último o que poderia colocar-se na base de um processo emancipatório, por meio da utopia de ação comunicacional isenta de coações para a construção de novos consensos normativos.

À luz das proposições dos dois últimos autores, frente ao problema apontado, não se trata, todavia, como lembra Habermas (1988) - ao considerar a ação instrumental um a priori da espécie humana e Ayres (2007) - que propõe a submissão da razão instrumental à prática, na qual os interesses humanos sobrepujem técnica que se autorreproduz, pretendendose apartada da realidade humana que a produziu - de abdicar da racionalidade instrumental, tampouco de prescindir do uso técnico de procedimentos que visam determinados fins. O que se quer chamar a atenção é que, nos serviços extra-hospitalares de saúde mental, as equipes profissionais, por meio da cisão entre tratamento clínico e ações de reabilitação psicossocial, com a desvalorização dessa última, atualizam a lógica segundo a qual uma racionalidade instrumental se impõe a uma prática, reproduzem um conjunto de técnicas, consolidadas dentro do rol tecnológico-científico que denominam clínica e que, independente do seu valor relacionado a uma eficácia, transformam-se em alternativas absolutas a quaisquer outras, por representarem ideologicamente o poder autolegitimável da ciência. Desse modo, as ações psicossociais são colocadas em segundo plano, pois se, como diz Peduzzi (1998), as práticas que se distanciam da tecnologia médico-clínica, ao se aproximarem da dimensão do cotidiano, são ideologicamente identificadas com o senso comum, percebe-se, imediatamente, a crença idealizadora de um espaço específico e imaginário para a reabilitação psicossocial, que não pode ser o serviço, pois esse é o espaço dos tratamentos, da clínica científica - práticas psicossociais, ao não serem preconizadas como científicas, são relegadas para outro lugar.

As práticas terapêuticas que se destacam da tecnologia médica são, portanto, colocadas à margem, secundarizadas, não negadas, mas idealizadas em outro serviço, instituição ou lugar onde, imaginariamente, haveria um especialista credenciado a realizá-las.

A reabilitação psicossocial inclui-se entre essas últimas, pois, como Saraceno (1999) salienta, esse conjunto de estratégias não se constitui em técnica ou em conjunto de técnicas, é antes uma postura ética, disposição de abertura às necessidades práticas dos portadores de sofrimento psíquico ou, como diz Ayres (2007), um encontro humano pautado por uma relação intersubjetiva "portadores de experiências e 
saberes diversos cada qual com sua sabedoria prática e instrumental ... como sujeitos das ações de saúde” (p.53).

\section{O acompanhamento terapêutico: uma clínica descentrada}

O acompanhamento terapêutico (AT) é um procedimento clínico que se realiza fora dos espaços institucionais, que busca a articulação do sujeito com o circuito social e a criação de espaços na cultura em que a diferença possa existir (Porto \& Sereno, 1991).

Um constituinte ético importante do AT é a busca permanente de desenvolvimento existencial do sujeito, um cuidado contínuo para com o outro sem retirálo do convívio social, a busca de significados vitais, um encontro humano no cotidiano que, ao mesmo tempo em que trata o sofrimento do sujeito, faz isso respeitando, sobretudo, sua cidadania, singularidade e humanidade (Barretto, 1997).

O AT permite que sujeitos, cujas constituições psíquicas peculiares determinam experiências particulares com o mundo compartilhado, possam articular suas formas singulares de percepção espaçotemporal à multiplicidade da vida urbana e cultural, às redes do tecido social, considerando um ponto de articulação entre as duas experiências, a do mundo socialmente compartilhado e as suas próprias (Palombini, 2004).

A prática do AT apresenta a possibilidade da conformação de um novo formato de clínica, a que Ayres (2007) chama de encontro humano entre dois sujeitos, superando o modelo tradicional em que o sujeito tratado encontra-se na posição de objeto.

Bezzerra (1996) sublinha, em contraposição a uma definição de sujeito essencialmente dada, o valor de uma clínica que dialoga com um sujeito aberto às multifacetadas produções da cultura e a sede das construções de novos modelos de subjetivação. Nesse conceito, a noção de sujeito desatrela-se da visão individualizada da subjetividade e passa a ser visto em completa conexão com a cultura e com a sociedade. Nessa perspectiva, a clínica deixa de lidar com uma pretensa interioridade psicológica, para ocupar-se da rede de subjetividades que envolve e constitui o sujeito. É, portanto, pensar uma clínica que aponte para uma multiplicação da capacidade do sujeito de ordenação de suas práticas psíquicas, sociais e políticas, de uma forma mais criativa.

O AT apresenta uma clara interface com as concepções de cuidado como as ressaltadas acima, assim como com as preconizadas para compor o conjunto de estratégias de um projeto de reabilitação psicossocial. Saraceno (1999) salienta que a clínica nesse modelo se constitui enquanto uma clínica do sujeito, na qual o foco encontra-se na pessoa que necessita de cuidado, e o essencial é a postura ética de buscar com o sujeito tratado produções de sentido que ressoem significativamente em sua vida, que the capacite a construir um cotidiano no qual ele seja autor e busque formas de superação de barreiras ao seu desenvolvimento humano e estabelecimento de cidadania.

O acompanhamento terapêutico, além disso, é uma prática terapêutica interdisciplinar, pois, além de receber contribuições teóricas e epistemológicas de vários campos do saber, tais como o psicológico, o antropológico, o sociológico, o filosófico, o político, o ocupacional e o ético, entre outros, é um exercício realizado efetivamente por vários profissionais das áreas da saúde e humanas. É exercício concreto de construção de cidadania e cuidado e possibilidade concreta de produção de um campo aberto composto por formas de comunicabilidade livre e democrática e fonte de acesso à criação de formas de interação dialógica.

De acordo com as perspectivas apontadas, o AT mostra-se como uma forma concomitante de exercício clínico, a partir do qual se abre a possibilidade de tratar o sofrimento por meio dos caminhos das redescrições da subjetivação e ressignificação de projetos de vida e de intervenção dentro do campo da atenção psicossocial, na medida em que constitui ação de devolução de direitos e reconstrução de um cotidiano no qual o insólito das existências particulares encontre expressão, valor e legitimidade. Nesse sentido, o AT constitui-se enquanto uma clínica descentrada, não se autolegitima com base em técnicas determinadas e predefinidas ao sujeito e propicia a interface com as ações de reabilitação psicossocial preconizadas pelos objetivos das reformas psiquiátrica e sanitária que propõem novas formas de tratar e cuidar do sujeito em sofrimento.

A inclusão da prática do AT na rede pública de saúde e saúde mental é uma realidade que, conforme Palombini (2004), contribui para a consolidação de práticas de atenção ao sofrimento psíquico, pautadas dentro dos princípios da reforma psiquiátrica, devendo "incluir, necessariamente, no âmbito do tratamento, além do corpo discursivo e do corpo biológico, o familiar e o social.” (p.25).

Contudo, segundo um estudo que avaliou os CAPS da região sul do país, os trabalhadores que cumprem essa função nos CAPS avaliados são aqueles que recebem os piores salários (Kantorski, 2007). 
Nessa mesma direção, Leão e Barros (2008) confirmam, com base em estudo em CAPS de município paulista, que a atividade do acompanhamento terapêutico fica sempre remetida a estagiários e nunca é vislumbrada como função a ser exercida pelos profissionais do serviço.

Entretanto, a relevância do acompanhamento terapêutico como atividade terapêutica para integrar os projetos terapêuticos dos serviços extrahospitalares de saúde mental da rede pública de saúde é inquestionável, pois constitui uma prática plural e descentrada que reúne, em seu próprio ato terapêutico, a clínica e a reabilitação psicossocial, colocandose como dispositivo fundamental para superação da dicotomia entre essas duas esferas de ação em saúde e saúde mental.

\section{Considerações finais}

Parcela importante dos serviços extrahospitalares da rede pública de saúde mental tem apresentado projetos terapêuticos aos usuários apoiados prioritariamente em ações pautadas pelo tratamento clínico no modelo médico-psicológico, colocando em segundo plano ações dentro da estratégia da reabilitação psicossocial. Nessa direção, esses serviços se distanciam das propostas e diretrizes do Projeto da Reforma Psiquiátrica, que concebe a atenção psicossocial como prioritária na composição das ações terapêuticas que constituem os programas dos serviços de saúde. Da mesma forma, esses serviços distanciam-se da missão ético-política de substituição aos modelos de exclusão e violência desenvolvidos na organização asilar e repetem historicamente exemplo de tratamento ao sofrimento psíquico apoiado no modelo hegemônico biomédico, tal como na forma asilar.

O conjunto de estratégias representado pela reabilitação psicossocial envolve ações e iniciativas que ultrapassam a esfera médico-clínica dos tratamentos, isto é, não ficam atreladas aos objetivos relacionados aos processos saúde-doença e não têm que, necessariamente, localizar-se nos equipamentos de saúde. Por ser um processo de remoção de barreiras à plena integração social de um indivíduo em desvantagem social que, por motivos diversos, conheceu impedimentos ao exercício pleno de seus direitos e de sua cidadania, promove junto com o sujeito condições para que ele possa voltar a se desenvolver socialmente.

O acompanhamento terapêutico tem se mostrado um procedimento valioso nesses serviços porque produz, por meio do próprio ato terapêutico, o tratamento do sujeito em sofrimento, assim como, ao ser desenvolvido no território e muitas vezes como ação comunitária, viabiliza a construção de aberturas, na tessitura social, de caminhos pelos quais o sujeito em sofrimento pode reconstruir sua cidadania, exercer seus direitos sociais e políticos e remover barreiras ao seu desenvolvimento humano.

\section{Referências}

Almeida, M. C. \& Oliver, F. C. (2001). Abordagens comunitárias e territórios em reabilitação de pessoas com deficiências: fundamentos para a terapia ocupacional. In M. P. De Carlo \& C. Bartalotti (Orgs.), Terapia Ocupacional no Brasil: fundamentos e perspectivas (pp.81-98.). São Paulo: Plexus Editora.

Amarante, P. (1995). A trajetória da reforma psiquiátrica no Brasil. In P. Amarante (Org.), Loucos pela vida: a trajetória da Reforma Psiquiátrica no Brasil (pp. 57 -90). Rio de Janeiro: SDE/ENSP.

Amarante, P. (1996). O homem e a serpente: outras histórias para a loucura e a psiquiatria. Rio de Janeiro: Editora Fiocruz.

Amarante, P. (2007). Saúde mental e atenção psicossocial. Rio de Janeiro: Editora Fiocruz.

Ayres, J. R. C. M. (2001). Sujeito, intersubjetividade práticas de saúde. Ciência e Saúde Coletiva, 6(1), 63 -72.

Ayres, J. R. C. M. (2007). Uma concepção hermenêutica de saúde. Phisis: Revista de Saúde Coletiva, 17(1), 43-62.

Barretto, K. D. (1997). Uma proposta de visão ética no acompanhamento terapêutico. In Equipe de Acompanhantes Terapêuticos do Instituto A Casa (Org.), Crise e cidade: acompanhamento terapêtico (pp. 241-268). São Paulo: EDUC.

Bezerra, B. (1996). A clínica e a reabilitação psicossocial. In A. Pitta (Org.), Reabilitação Psicossocial no Brasil (pp. 137142). São Paulo: Hucitec.

Kantorski, L. P. (Coord.). (2007). CAPSUL - Avaliação dos CAPS da região sul do Brasil: Relatório. Pelotas, RS: Conselho Nacional do Desenvolvimento Científico e Tecnológico (CNPq), Ministério da Saúde.

Fiorati, R. C. (2006). Acompanhamento Terapêutico: uma estratégia terapêutica em uma unidade de internação psiquiátrica. Dissertação de Mestrado, Escola de Enfermagem de Ribeirão Preto, Universidade de São Paulo.

Habermas, J. (1987). Técnica e ciência como ideologia. In J. Habermas, Técnica e ciência como ideologia (pp. 42-92). Lisboa: Edições 70.

Habermas, J. (1988). Teoría de la acción comunicativa. Madrid: Taurus.

Leão, A. \& Barros, S. (2008). As representações sociais dos profissionais de saúde mental acerca do modelo de atenção e as possibilidades de inclusão social. Saúde Sociedade, 17(1), 95-106.

Onocko-Campos, R. T. \& Furtado, J. P. (2006). Entre a saúde coletiva e a saúde mental: um instrumental metodológico para avaliação da rede de Centros de Atenção Psicossocial (CAPS) do Sistema Único de Saúde. Cadernos de Saúde Pública, 22(5), 1053-1062. 
Palombini, A. L. (2004). Acompanhamento terapêutico na rede pública: a clínica em movimento. Porto Alegre: Editora da UFRGS.

Peduzzi, M. (1998). Equipe Multiprofissional de Saúde: a interface entre trabalho e interação. Tese de Doutorado, Departamento de Medicina Preventiva e Social da Faculdade de Ciências Médicas da Universidade Estadual de Campinas, Campinas, SP.

Porto, M. \& Sereno, D. (1991). Sobre o acompanhamento terapêutico. In Equipe de Acompanhantes Terapêuticos do Hospital-Dia A Casa (Org.), A rua como espaço clínico (pp. 23-30). São Paulo: Escuta.

Saraceno, B. (1999). Libertando identidades. Belo Horizonte: Tè Corá; Rio de Janeiro: Instituto Franco Baságlia.

Wetzel, C. (2005). Avaliação de serviço em saúde mental: a construção de um processo participativo. Tese de Doutorado, Escola de Enfermagem de Ribeirão Preto, Universidade de São Paulo, São Paulo.

Recebido em: 12/10/2009

Aceite em: 01/08/2013

Regina Célia Fiorati é Docente do Curso de Terapia Ocupacional da Faculdade de Medicina de Ribeirão Preto da Universidade de São Paulo. Endereço: R. Graciliano Ramos 100. Ribeirão Preto/SP, Brasil. CEP 14051039. E-mail: reginacf@ffmrp.usp.br

\section{Como citar:}

Fiorati, R. C. (2013). Acompanhamento terapêutico, clínica e atenção psicossocial: uma relação possível? Reflexão crítica segundo a hermenêutica dialética de Jügen Habermas. Psicologia \& Sociedade, 25(n. spe. 2), 82-89. 